\title{
Computerised tomography and acute traumatic head injury: time for change?
}

Department of Accident and Emergency Medicine, Bristol Royal Infirmary, Bristol BS2 8HW, United Kingdom J Cranshaw G Hughes M Clancy Correspondence to Mr M Clancy.

\author{
J Cranshaw, G Hughes, M Clancy
}

\begin{abstract}
The aim was to reconsider the "Guidelines for initial management of head injury in adults" - particularly with respect to the indications for computerised tomographic (CT) scanning - suggested by "a group of neurosurgeons" over a decade ago and still followed in some accident and emergency (A\&E) departments. These recommendations are placed in the context of more recent research and the increased number of A\&E departments with on-site rapid access to a CT scanner but without a resident neurosurgical facility. A case can be made for an updated policy with more liberal indications for CT scanning of acutely head injured adults in periph-
\end{abstract}

Table 1 Guidelines for initial management after head injury in adults

For skull $x$ ray examination after recent head injury

1 Loss of consciousness or amnesia at any time

2 Neurological symptoms or signs

3 Cerebrospinal fluid or blood from the nose or ear

4 Suspected penetrating injury

5 Scalp bruising or swelling

For admission to a general hospital

Confusion or any other depression of the level of

consciousness at the time of examination

2 Skull fracture

3 Neurological symptoms or signs

Difficulty in assessing the patient - for example, alcohol, epilepsy, or other medical condition

5 Lack of a responsible adult to supervise the patient; other social problems

Note - brief amnesia after trauma with full recovery is not sufficient indication for admission. Relatives or friends of patients sent home should receive written advice about changes that would require the patient to be returned urgently to hospital.

For consultation with a neurosurgeon

1 Fractured skull with any of the following: confusion or worse impairment of consciousness, one or more epileptic fits, or any other neurological symptoms or signs

2 Coma continuing after resuscitation - even if no skull fracture

3 Deterioration in level of consciousnes

4 Confusion or other neurological disturbances persisting for more than eight hours, even if there is no skull fracture

Depressed fracture of the skull vault

6 Suspected fracture of the base of skull (cerebrospinal fluid rhinorrhoea or otorrhoea, bilateral orbital haematoma, mastoid haematoma, or evidence of penetrating type of injury such as spike or gunshot) eral A\&E departments. However, calculating the cost-efficiency of more frequent use of what is now a common but relatively expensive resource would remain a challenge.

( 7 Accid Emerg Med 1996;13:80-85)

Key terms: computerised tomography; accident and emergency; head injuries

In 1983, when the guidelines for initial management of head injury were discussed by radiologists and neurosurgeons under the auspices of the DHSS at Harrogate, ${ }^{1}$ computerised axial tomography (CT) scanners were predominantly located in neurosurgical referral centres. The guidelines of $1984^{2}$ (table 1) therefore "assume a situation where 24 hour scanning facilities are limited to the regional centre, so that access is available only to selected patients," and only the triage tools of history, examination, and skull radiology are envisaged as available to peripheral accident and emergency (A\&E) departments. With these indirect indicators of intracranial events, acutely head injured patients can be assigned to "high", "intermediate", and "low" risk groups ${ }^{3}$ with respect to the possible development of a surgically significant traumatic intracranial haematoma and management decisions taken on this basis. A revised risk assessment for these groups, together with their expected proportion of all A\&E acute head injury attendees is presented in table $2 .^{4}$

\section{Argument and discussion}

Figure 1 contains a decision diagram based on the 1984 guidelines. By following the different clinical characteristics of acutely head injured patients through the network, it can be seen that patients with externally apparent neurosurgical problems or in coma [Glasgow coma score (GCS) 3-8] should be referred immediately for neurosurgical assessment and scanning. Later, patients with neurological symptoms or signs who have also been found to have

Table 2 Type of head injury, risk of surgically significant traumatic intracranial haematoma (TIH) and expected proportions of $A \mathcal{E} E$ attendees with head injuries and surgically treated TIH (after ${ }^{4}$ )

\begin{tabular}{|c|c|c|c|}
\hline Risk of surgically significant TIH & $\begin{array}{l}\text { Absolute risk of surgically } \\
\text { significant TIH in adults }\end{array}$ & $\begin{array}{l}\text { Percent of } A \mathcal{E} E \text { attendees } \\
\text { with head injuries }\end{array}$ & $\begin{array}{l}\text { Percent of surgically } \\
\text { treated TIH }\end{array}$ \\
\hline $\begin{array}{l}\text { High risk } \\
\text { Coma (GCS } \leq 8 \text { ) } \\
\text { Skull fracture with neurological symptoms or signs }\end{array}$ & $\begin{array}{l}1 \text { in } 8 \\
1 \text { in } 5\end{array}$ & $\begin{array}{l}1 \% \\
0 \cdot 4 \%\end{array}$ & $\begin{array}{l}47 \% \\
29 \%\end{array}$ \\
\hline $\begin{array}{l}\text { Intermediate risk } \\
\text { Skull fracture and GCS } 15 \\
\text { GCS 9-14 }\end{array}$ & $\begin{array}{l}1 \text { in } 45 \\
1 \text { in } 180\end{array}$ & $\begin{array}{l}1 \cdot 3 \% \\
5 \cdot 4 \%\end{array}$ & $\begin{array}{l}10 \% \\
11 \%\end{array}$ \\
\hline $\begin{array}{l}\text { Low risk } \\
\text { Fully conscious without skull fracture }\end{array}$ & 1 in 7866 & $91 \cdot 8 \%$ & $3 \%$ \\
\hline
\end{tabular}

GCS, Glasgow coma score. 


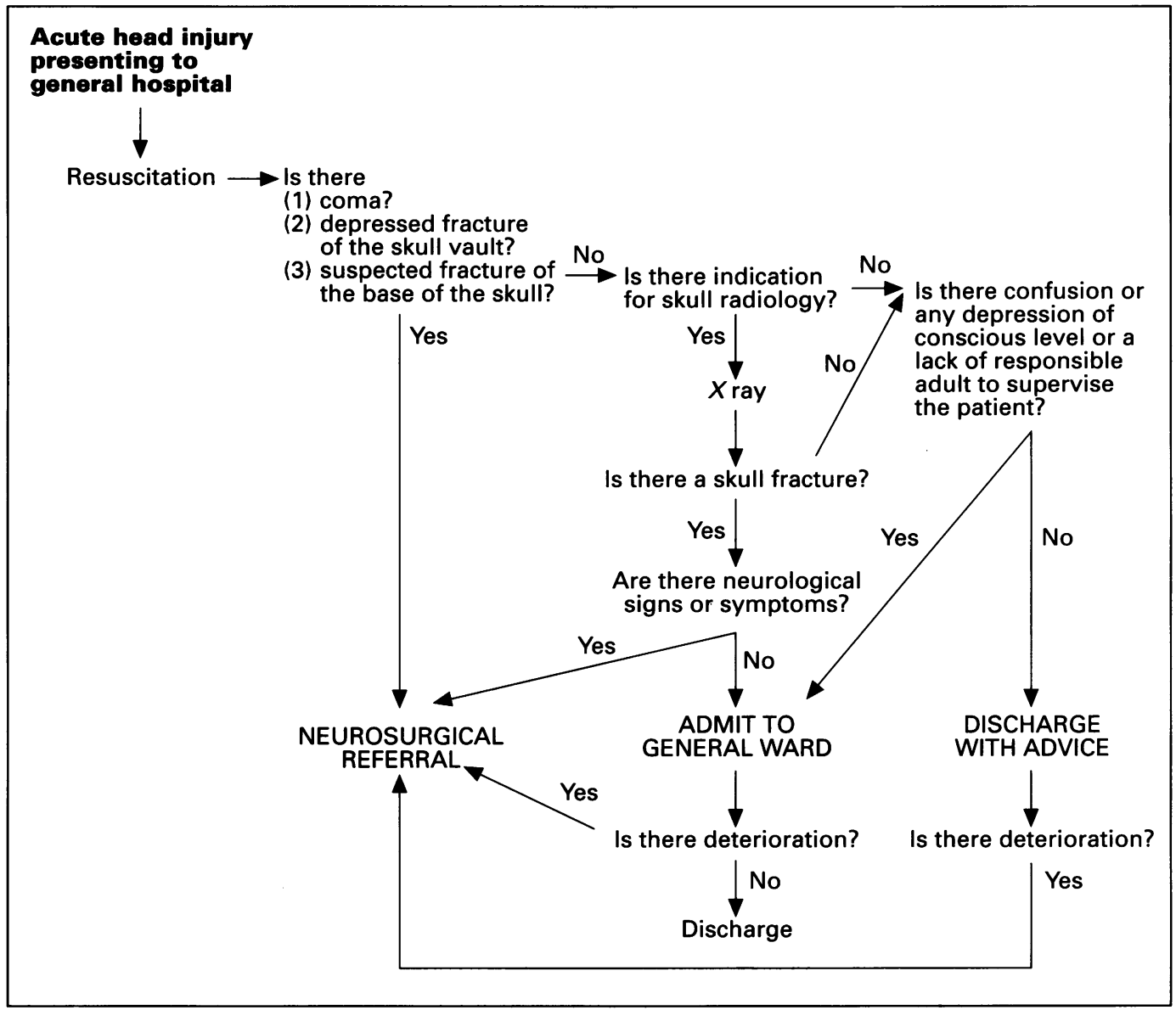

Figure 1 A decision diagram based on the 1984 guidelines for initial management of head injury in adults. ${ }^{2}$

a skull fracture will be referred. Later still, others can "earn" their referral either by failing to improve within $8 \mathrm{~h}$ or by deteriorating under observation in hospital or at home. In the text of the 1984 paper, the justification given for this particular prioritisation of peripheral hospital and neurosurgical centre resources is that "earlier investigation of patients at high risk of an intracranial complication will improve considerably the overall results", and it is accepted that "without an increase in facilities for CT, it may not be feasible to scan urgently" those patients at intermediate risk. It is now appreciated that while patients in the intermediate risk group may constitute only $7 \%$ of all patients presenting with acute head injuries to $\mathrm{A} \& \mathrm{E}$ departments, this group contains up to one third of all surgically significant traumatic intracranial haematomas. ${ }^{4}$ The institution of the 1984 guidelines has improved morbidity and mortality for victims of acute head injuries. ${ }^{5}$ However, as peripheral hospital scanning capability has increased to a size where the urgent scanning of intermediate risk patients may be feasible, how should we aim to improve our practice further? The aim of head injury management is to prevent avoidable morbidity and mortality. Two principal observations from recent research in the field of head injury outcome are pertinent.

The first observation is that improved outcome for patients with traumatic intracranial haematoma has been shown to be related to earlier identification of the neurosurgical problem..$^{5-7}$ The desire to promote this improvement was expressed at the end of the 1984 guidelines: "More patients need to go to a neurosurgical unit for computed tomography and to reach there sooner than many do at present." If a traumatic intracranial haematoma is suspected, CT scanning should be an early investigation. An immediate benefit of early CT scanning should be a reduction in the practice of waiting and watching at-risk patients on peripheral hospital wards for physical signs that may occur late in the evolution of traumatic intracranial haematoma and secondary brain damage. In-hospital observation has been criticised as both inefficient and costly. ${ }^{12} 13$ If patient deterioration occurs, the outcome is likely to be better if it occurs in a neurosurgical centre after early identification of the potential problem and timely transfer.

The second observation is that improved outcome for acutely head injured patients as a whole group may now fundamentally rely on extending indications for CT scanning to lower risk patients. Evidence that a "substantial minority" of clinically low risk patients with traumatic intracranial haematoma in the United Kingdom are poorly served by the 1984 guidelines, with resultant excessive morbidity and mortality, has been presented. ${ }^{14}$ Similarly, in North America, a comparison of head injury outcome between 41 hospitals suggested that "reduction in mortality for hospitalised patients is not likely to be due to spectacular 
saving of high risk patients, but due to the prevention of deterioration in patients who initially appear to be at low risk", and further that "the patients at greatest risk of inadequate diagnosis and treatment are not those at high risk who might or might not be saved by highly specialised intensive care, but are those who are predicted to be at relatively low risk". ${ }^{15}$ In addition, it is likely that low risk patients in whom neurosurgically significant problems are diagnosed quickly and managed expertly may have better outcomes than those with high risk clinical characteristics who are at present automatically referred. Extending CT scanning to patients at lower risk of traumatic intracranial haematoma may be more cost-efficient than continuing to allocate resources in the bias justified in the 1984 guidelines, but how wide should we cast the scanning net?

Teasdale et al have suggested "the optimum approach would be for all patients with persisting impaired consciousness (defined as GCS 9-14) or coma to have CT". ${ }^{4}$ They have also advised extending "the indications for CT to include patients who have a skull fracture who are fully conscious". Based on data from Scottish A\&E departments, this policy would entail an extra $1200 \mathrm{CT}$ scans per million population per year but "should achieve the early detection of $95 \%$ of intracranial haematoma. A remediable haematoma would be disclosed in $3 \%$ of the patients investigated. In another $5-10 \%$, CT would show an abnormality requiring expert neurological assessment". An 18 month survey in the Emilia-Romagna region of Italy where these recommendations were adopted for adult patients supported these predictions. ${ }^{16}$

One problem encountered by lowering the clinical threshold for CT scanning in this Italian study was that some patients presented neurosurgeons with difficult choices between surgical and conservative management. However, this was tolerated as being "far better than the 'inadvertent conservative management' of the past". Some concern has also been expressed about the possibility of obtaining a falsely reassuring normal result by so called "ultra-early" or "zero time" CT scanning and an acutely head injured patient who then deteriorates because of the subsequent development of a traumatic intracranial haematoma. ${ }^{10}$ This problem has been especially experienced in patients with traumatic extradural haematoma. However, one study concluded that "one should not generalise or speculate that perhaps all extradural haematoma are delayed if CT is performed early in all cases of head injury". ${ }^{11}$ Delayed extradural haematoma is characterised by, among others, signs of significant primary brain injury and skull fracture. Therefore, regardless of the initial CT result, patients with these characteristics should be referred and carefully monitored in a neurosurgical centre. Whether early CT scanning might prejudice other types of acute head injury can only be resolved when more data are available. At present such fears should not deter one from adopting early CT scanning, which has already been shown to improve overall outcome.

In the USA, imaging recommendations after acute head injury were made by a multidisciplinary review panel in $1987^{17}$ (see table 3), but with variable clinical uptake. ${ }^{18-20}$ In recent years, the loose recommendation to "consider CT scanning" for patients at "moderate" risk of intracranial injury has been applied to the extent that all such head injuries are now imaged in some centres. A further inclination, if not indication, to perform a CT scan is the American medicolegal climate that has "zero tolerance" for the albeit remote possibility of a patient considered at "moderate" risk of intracranial injury ultimately becoming neurologically devastated or dying without receiving the benefit of an early CT scan. ${ }^{10}$ Thus, although a great deal of retrospective American data and comment have been published about the percentage of "abnormal" CT scans in various acutely head injured populations and related patient characteristics, ${ }^{21}{ }^{22}$ the criteria for CT scanning the patients studied are rarely explicit $^{2324}$ and not all relevant patients in

Table 3 Management strategy for radiographic imaging in patients with head trauma in the USA ${ }^{17}$

\begin{tabular}{|c|c|c|}
\hline Low risk group, possible findings & Moderate risk group, possible findings & High risk group, possible findings \\
\hline $\begin{array}{l}\text { - Asymptomatic } \\
\text { - Headache } \\
\text { - Dizziness } \\
\text { - Scalp haematoma } \\
\text { - Scalp laceration } \\
\text { - Scalp contusion or abrasion } \\
\text { - Absence of moderate risk or high risk } \\
\text { criteria }\end{array}$ & $\begin{array}{l}\text { - History of change of consciousness at } \\
\text { the time of injury or subsequently } \\
\text { - History of progressive headache } \\
\text { - Alcohol or drug intoxication } \\
\text { - Unreliable or inadequate history of } \\
\text { injury } \\
\text { - Age less than } 2 \text { years (unless injury } \\
\text { very trivial) } \\
\text { - Post-traumatic seizure } \\
\text { - Vomiting } \\
\text { - Post-traumatic amnesia } \\
\text { - Multiple trauma } \\
\text { - Serious facial injury } \\
\text { - Signs of basilar fracture } \\
\text { - Possible skull penetration or depressed } \\
\text { - Sracture }\end{array}$ & $\begin{array}{l}\text { - Depressed level of consciousness not } \\
\text { clearly due to alcohol, drugs, or other } \\
\text { cause (eg, metabolic and seizure } \\
\text { disorders) } \\
\text { - Focal neurological signs } \\
\text { - Decreasing level of consciousness } \\
\text { - Penetrating skull injury or palpable } \\
\text { depressed fracture }\end{array}$ \\
\hline $\begin{array}{l}\text { Recommendations } \\
\text { - Observations alone: discharge patients } \\
\text { with head injury information sheet } \\
\text { (listing subdural precautions) and a } \\
\text { second person to observe them. }\end{array}$ & $\begin{array}{l}\text { Recommendations } \\
\text { - Extended close observation (watch for } \\
\text { signs of high risk group) } \\
\text { - Consider CT examination and } \\
\text { neurosurgical consultation } \\
\text { - Skull series may rarely be helpful if } \\
\text { positive, but does not exclude } \\
\text { intracranial injury if normal. }\end{array}$ & $\begin{array}{l}\text { Recommendations } \\
\text { - Patient is a candidate for neurosurgical } \\
\text { consultation or emergency CT } \\
\text { examination or both. }\end{array}$ \\
\hline
\end{tabular}


studies are CT scanned, ${ }^{10}{ }^{25}$ with resulting unknown selection bias.

While up to date guidelines for CT scanning of acutely head injured patients have not been formulated in a way that would satisfy all concerned physicians in the USA, one opinion is that "most (if not all) physicians would recommend urgent CT scans for all patients with GCS of 14 or less". ${ }^{26}$ However, some believe the "numbers (of significant abnormalities on CT scans) are high enough to mandate routine early CT scanning on all patients with a history of loss of consciousness even with GCS 15 ". ${ }^{27}$

These recommendations are supported by a prospective $e^{102628}$ and a retrospective ${ }^{29}$ study, each of over 700 routinely CT scanned patients with "minor" head injuries, defined as GCS 13-15 and a history of loss of consciousness. Some of the results are presented in table 4 . One should be cautious about drawing conclusions from these data. An impression of expected numbers of "abnormal" scans, defined individually for each study in table 4, can be gained in patients with "minor" head injuries, but actual frequencies of different cranial and intracranial abnormalities and temporally related neurosurgical interventions by GCS group are unavailable. Obviously, an "abnormal" scan only becomes surgically significant when viewed through the eyes of the responsible neurosurgeon and in the context of the clinical state of the patient. It is also of note that in a prospective study patients might not be scanned for 6-8 hours and the two patients with initial GCS 15 who required neurosurgery "announced their need for CT scanning by developing focal neurological signs or deteriorating". ${ }^{26}$

It is noteworthy that the predominant causes of head injuries in Brooklyn and New Jersey, where the studies originate, may differ significantly from anywhere in the United Kingdom. It is therefore impossible to extrapolate a potential workload generated by following similar guidelines here. However, an important observation from the American data is that GCS can be used to predict an inversely proportional yield of abnormal CT scans and, by inference, surgically significant abnormalities. A specific GCS greater than or equal to 13 , therefore, could be used as one criterion for early CT scanning of acutely head injured patients. This would increase the number of abnormalities detected but the ratio of scans to significant abnormalities becomes less costefficient as the threshold score rises. In the Bristol Royal Infirmary, an agreement has been reached between A\&E specialists, neurosurgeons, and radiologists to scan all patients with GCS less than or equal to 13 as soon as possible.

\section{Conclusions}

A decision diagram for the management of head injured adults using GCS less than or equal to 14 and a skull fracture as indications for early CT scanning is shown in fig 2 . In comparison to fig 1, where up to two thirds of surgically significant traumatic intracranial haematomas should reach rapid neurosurgical referral, ${ }^{3} 95 \%$ are now referred. ${ }^{4}$ This is at an extra cost to $A \& E$ departments of CT scanning $7 \%$ of head injury attendees, an estimated 1200 patients per million population per year shared among departments with CT scanners serving a neurosurgical centre. A saving is made in that $5.8 \%$ should no longer receive skull $\mathrm{x}$ rays, as indicated by the 1984 guidelines. Neurosurgical resources may be put to more efficient use. More than one third of initial scans of acutely head injured patients performed after referral to one regional neurosurgical unit were normal and a subsequent scan in the "acute" period showed new abnormalities in only $1 \% .^{30}$ None of these patients required evacuation of a traumatic intracranial haematoma, but actual diagnosis, treatment, and outcome in this group were not published.

A potential further saving is possible if the prognostic value of a normal CT scan could be realised but this remains to be quantified. It has been suggested that "patients whose tomogram is normal may either not need to be admitted or might be discharged early". "The reassuring nature of a normal CT scan in patients with "minor" head injuries has been provided indirectly by American studies of these patients that generate large numbers of patients with normal CT scans, none of whom have gone on to require neurosurgery. ${ }^{12} 252629$ Small retrospective $^{31}$ and prospective studies ${ }^{12}$ in the USA have been performed to support a policy of discharge of patients with "minimal" head injuries (defined as GCS 14 or 15 with a history of loss of consciousness or amnesia) from $A \& E$ departments who have a normal

Table 4 Two recent studies of minor head injuries in the USA. Entry criteria: GCS 13-15 and a history of lost consciousness or amnesia

\begin{tabular}{|c|c|c|c|c|c|c|c|}
\hline \multirow[t]{2}{*}{$\begin{array}{l}\text { Study } \\
\text { reference }\end{array}$} & \multirow[t]{2}{*}{ Study type } & \multirow[t]{2}{*}{$\begin{array}{l}\text { Additional } \\
\text { entry criteria }\end{array}$} & \multirow[t]{2}{*}{$\begin{array}{l}\text { Timing of } \\
\text { CT scan }\end{array}$} & \multirow[t]{2}{*}{$\begin{array}{l}\text { Definition of } \\
\text { CT abnormality }\end{array}$} & \multicolumn{3}{|c|}{$\begin{array}{l}\text { Per cent of patients with abnormal } \\
C T \text { scans by GCS }\end{array}$} \\
\hline & & & & & 13 & 14 & 15 \\
\hline 29 & Retrospective & $\begin{array}{l}\text { No focal neurological } \\
\text { deficit } \\
\text { Exclusion of } \\
\text { penetrating injury } \\
\text { not specified } \\
\text { Age not specified }\end{array}$ & Immediate & $\begin{array}{l}\text { Any skull fracture or } \\
\text { intracranial } \\
\text { trauma }\end{array}$ & $37 \cdot 5$ & $24 \cdot 2$ & $\begin{array}{r}13.2 \text { (9.4 intracranial lesion) } \\
(1.7 \text { underwent surgery })\end{array}$ \\
\hline $10,26,28$ & Prospective & $\begin{array}{l}\text { Penetrating injury } \\
\text { excluded } \\
\text { Adults only (18+) }\end{array}$ & $\begin{array}{l}\text { Unspecified but } \\
\text { patients could } \\
\text { wait "several" } \\
\text { (6-8) hours }\end{array}$ & $\begin{array}{l}\text { Skull fracture } \\
\text { (excluding linear } \\
\text { skull fracture) or } \\
\text { intracranial } \\
\text { trauma }\end{array}$ & 41 & 19 & $9.4(0.3$ underwent surgery) \\
\hline
\end{tabular}

CT, computerised tomography; GCS, Glasgow coma scale. 


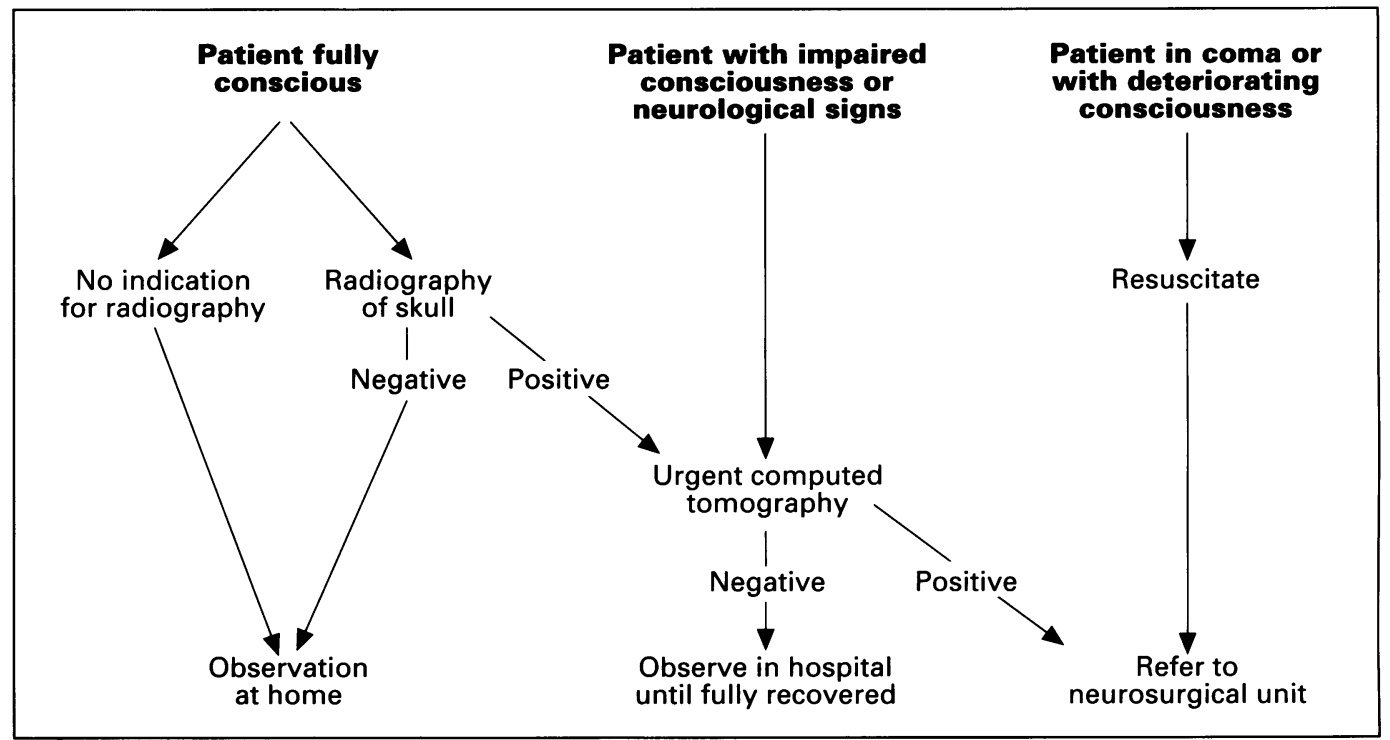

Figure 2 A decision diagram based on possible new adult head injury management guidelines (after ${ }^{4}$ ).

neurological examination and CT scan. Patients in the prospective study $^{12}$ were allowed to sober up if necessary, were reexamined before discharge, and were allowed home regardless of whether there was someone at home to observe them. By American criteria, ${ }^{17}$ admission was avoided in more than $80 \%$ of patients and these were apparently discharged safely within 3-12 hours.

In practice it is unlikely that a patient with GCS less than 15 or neurological signs or symptoms could be discharged from an A\&E department. However, the question of whether CT scanning acute head injuries, as a less expensive option, could or should be used to reduce the number of admissions is raised by these observations. Specifically, it could be asked, at what confidence level and costefficiency could neurologically normal patients with GCS 15 and intracranially normal CT scans be discharged whose "social condition, or lack of responsible adult or relative", or whose assessment was difficult due to "alcohol, epilepsy or other medical condition" or whose skull fracture would normally mandate admission by the 1984 guidelines? This group of individuals routinely occupies a not insignificant bed space of whichever specialty observes head injuries, particularly in inner city hospitals. For regular attenders of $A \& E$ departments with acute head injuries the risks of repetitive exposure to $x$ irradiation by CT might have to be taken into consideration, as might the possible risks of general anaesthesia required to obtain some scans. More large studies are required.

One important standard laid down in the 1984 guidelines remains. Any change in CT scanning policy for acutely head injured patients in peripheral A\&E departments should be by agreement with radiologists and the local neurosurgical referral centre. When new criteria are decided then "a consensus about what management is locally appropriate could appreciably improve the overall care of head injuries in a region. But this would only happen if the agreed policy became widely known, especially among junior staff - who are everywhere the most directly concerned with these patients".

1 Lewis F, ed. The management of acute head injury. Harrogate Seminar Report 8. London.: DHSS 1-85, 1983.

2 Briggs M, Clarke P, Crockard A, et al. Guidelines for initial management after head injury in adults. Suggestions from management after head injury in adults. Suggestio

3 Mendelow A, Teasdale G, Jennett B, et al. Risks of intracranial haematoma in head injured adults. BMf 1983; cranial haemat

4 Teasdale G, Murray G, Anderson E, et al. Risks of acute traumatic instant haematoma in children and adults: implications for managing head injuries. $B M F$ 1990; 300:363-7.

5 Miller J, Tocher J, Jones P. Extradural haematoma - earlier detection, better results. Brain Injury 1988;2:83

6 Bricolo A, Pasut L. Extradural haematoma towards zero mortality. Neurosurgery 1984;14:8-12.

7 Teasdale G, Galbraith S, Murray L, et al. Management of traumatic intracranial haematoma. $B M \mathcal{F}$ 1982;285: 1695-7.

8 Smith $\mathrm{H}$, Miller J. The danger of an ultra-early computed tomographic scan in a patient with an evolving epidural haematoma. Neurosurgery 1991;29:258-60.

9 Mohanty S, Thompson W, Rakower S. Are CT scans for head injury patients always necessary? $f$ Trauma 1991; 31:801-5.

10 Jeret J, Mandell M, Anziska B, et al. Clinical predictors of abnormality disclosed by CT after mild head trauma. Neurosurgery 1993;32:9-15.

11 Poon W, Rehman S, Poon C, Li A. Traumatic extradural haematoma of delayed onset is not a rarity. Neurosurgery haematoma of

12 Livingston D, Loder P, Koziol J, Hunt C. The use of CT scanning to triage patients requiring admission following minimal head injury. $\mathcal{F}$ Trauma $1991 ; 31: 483-7$.

13 Stein S, O'Malley K, Rolls S. Is routine tomographic scanning too expensive for mild head injury? Ann Emerg Med 1991;20:1286-9.

14 Miller J, Murray L, Teasdale G. Development of traumatic intracranial haematoma after "mild" head injury. Neurosurgery 1990;27:669-73.

5 Klauber M, Marshall L, Luersson T, et al. Dominants of head injury mortality: importance of the low risk patient. Neurosurgery 1989;24:31-6.

16 Servadei F, Vergoni G, Nasi M, et al. Management of lowrisk head injuires in an entire area: results of an 18 month survey. Surg Neurol 1993;39:269-75.

17 Masters S, McClean P, Arcarese J, et al. (1987) Small X-ray examinations after head trauma. Recommendations by a
multidisciplinary panel and validation study. $N$ Engl $\mathcal{F}$ Med 1987;316:84-91.

18 Yealy D, Hogan D. Imaging after head trama. Who needs what? Emerg Med Clin North Am 1991;9:707-17.

19 Taheri P, Karamanoukioni H, Gibbons XC, et al. Can patients with minor head injuries be safely discharged patients with minor head injuries

20 Hackney D. Skull radiography in the evaluation of acute head trauma: a survey of current practice. Radiology head trauma: a

21 Reinus W, Wippold F, Erickson K. Practical selection criteria for noncontrast cranial computed tomography in 
patients with mild head trauma. Ann Emerg Med $1993 \cdot 22 \cdot 1148-55$

22 Reinus W, Erickson K, Wippold F. Unenhanced emergency cranial CT: optimising patient selection with univariate and multivariate analyses. Radiology 1993;186:763-8.

23 Schynoll W, Overton D, Krane R, et al. A prospective study

to identify high yield criteria associated with acute

intracranial CT findings in head-injured patients. $A m \mathcal{J}$ Emerg Med 1993;11:321-6.

24 Ditrich A, Bowman M, Ginn-Pease M, et al. Pediatric head injuries: can clinical factors reliably predict an abnormality on CT? Ann Emerg Med 1993;22:1535-40.

25 Shackford S, Wald S, Ross S, et al. (1992) The clinical utility of computed tomographic scanning and neurologic examination in the management of patients with minor head injuries. J Trauma 1992;33:385-94.

26 Jeret J 7 Trauma 1993;35:490 [correspondence]

27 Jerin J Trama 19.35:40 [cospondence].

28 Jeret J, Mandell M, Avitable J. "Mild" head trauma: deceptive term [abstr]. Neurology 1993;43:A218.

29 Stein S, Ross S Mild head injury: a plea for routine early Ctein S, Ross S. Mild head injury: a plea

30 Machning. Trauma $1992,33.11-13$. $T$. Scanning and Macpherson P, Jennett B, Anderson E. CT scanning and
surgical treatment of 1551 head injured patients admitted to a regional neurosurgical unit. Clin Radiol 1990; 42:85-7.

31 Livingston D, Loder P, Hunt C. Minimal head injury is admission necessary? Am Surg 1991;57:14-17.

\section{ADVANCED LIFE SUPPORT GROUP}

\section{Major Incident Medical Management and Support}

Courses: to be held in various centres throughout the UK in 1996. This is a three day course in "life support style" designed to train health service personnel to provide an effective response at a major incident.

Fee $£ 300.00$

Advanced Paediatric Life Support Courses: to be held in various centres throughout the UK in 1996. This is a three day course designed to provide training which will enable doctors and nurses to deal efficiently with all paediatric emergencies. The course is modular and has sections on paediatric resuscitation, serious illness and serious injury.

Fee varies according to centre. Range $£ 300.00-£ 350$.00.

Inquiries for both courses to:

Jenny Antrobus

Advanced Life Support Group

A\&E Dept

Hope Hospital

Stott Lane

Salford M6 8HD

Tel 01617874345 